\title{
Management of postoperative ileus: focus on alvimopan
}

\author{
Eric L Marderstein \\ Conor P Delaney \\ Division of Colorectal Surgery, \\ Department of Surgery, University \\ Hospitals Case Medical Center, Case \\ Western, Reserve School of Medicine, \\ Cleveland, Ohio, USA
}

\begin{abstract}
Postoperative ileus (POI) is a transient loss of coordinated peristalsis precipitated by surgery and exacerbated by opioid pain medication. Ileus causes a variety of symptoms including bloating, pain, nausea, and vomiting, but particularly delays tolerance of oral diet and liquids. Thus POI is a primary determinant of hospital stay after surgery. 'Fast-track' recovery protocols, opioid sparing analgesia, and laparoscopic surgery reduce but do not eliminate postoperative ileus. Alvimopan is a mu opioid receptor antagonist that blocks the effects of opioids on the intestine, while not interfering with their centrally mediated analgesic effect. Several large randomized clinical trials have demonstrated that alvimopan accelerates the return of gastrointestinal function after surgery and subsequent hospital discharge by approximately 20 hours after elective open segmental colectomy. However, it has not been tested in patients undergoing laparoscopic surgery and is less effective in patients receiving nonsteroidal antiinflammatory agents in a narcotic sparing postoperative pain control regimen. Safety concerns seen with chronic low dose administration of alvimopan for opioid bowel dysfunction have not been noted with its acute use for POI.
\end{abstract}

Keywords: alvimopan, postoperative ileus, gastrointestinal surgery

\section{Introduction}

Postoperative ileus (POI) is defined as a transient cessation of coordinated bowel motility after surgical intervention which prevents effective transit of intestinal contents or tolerance of oral intake (Delaney et al 2006). It is inevitable that some degree of ileus will accompany any surgical procedure but the duration is strongly influenced by the type, location, and duration of the surgical procedure and is often exacerbated by intraoperative and postoperative pain control medication. Intestinal surgery is most commonly associated with the development of ileus, likely related to mechanical manipulation of the intestine. This can be demonstrated experimentally in animals such that progressive increases in manipulation of the intestine at surgery results in prolonged postoperative intestinal transit times, more dyscoordination of intestinal contractions and increased production of inflammatory mediators in the intestinal wall (Kalff et al 1998). Time to return of gastrointestinal function and the ability to tolerate an oral diet are of key importance in defining length of hospital stay, and patients are not discharged until they can independently maintain adequate oral nutrition. The costs of surgical care are generally divided into two major components: the cost of the operative procedure and the cost of postoperative care (Delaney et al 2003). A major determinant of the cost of postoperative care is the length of hospital stay. As a result, interventions that can reduce the duration of POI reliably by one day reduce reduce hospital costs and improve bed availability. What frustrates clinicians is that although one can generally predict when a normal POI is likely to resolve, a certain fraction of patients develop a prolonged ileus that can unpredictably last many days longer, requiring parenteral nutrition, a nasogastric tube, and prolonged hospitalization.
Correspondence: Eric Marderstein

I I 100 Euclid Avenue, Lakeside 7th Floor, Cleveland, $\mathrm{OH} 44124$, USA

$\mathrm{Tel}+\mathrm{I} 2168447120$

Fax + I 2168445957

Email eric.marderstein@uhhospitals.org
Therapeutics and Clinical Risk Management 2008:4(5) I-9

Page numbers not for citation purposes 
Although this can be secondary to a complication such as intrabdominal abscess, it can also occur with an obvious precipitating cause, termed primary POI.

Traditional postoperative care used to include the routine use of nasogastric drainage until documented evidence of return of gastrointestinal function was present, at which time a diet was gradually introduced. One lesson of the past two decades is that length of stay after abdominal surgery can be safely reduced with the use of 'fast-track' or 'enhanced' recovery protocols (Delaney et al 2001, 2003; Basse et al 2004). Orogastric tubes are removed prior to extubation as their routine use during the postoperative period has consistently been shown to be of no benefit after abdominal surgery and increases discomfort (Vermeulen et al 2006). Patients are encouraged to ambulate early after surgery and several times daily thereafter (Waldhausen and Schirmer 1990) and are offered liquids as early as the evening of surgery. Analgesia is more carefully tailored and includes opiates supplemented with ketorolac, and even gabapentin to reduce susceptibility to pain. If oral fluids are tolerated, patients are offered solid food prior to the return of bowel function. Patient-controlled analgesia (PCA) is switched to oral opioid analgesia on postoperative day two if liquids are being tolerated. It has not been our practice to use epidural analgesia as a randomized trial comparing 'fast-track' recovery with PCA versus epidural analgesia offered no advantages (Zutshi et al 2005).

Laparoscopic surgery offers additional benefits in reducing POI. Reduced contact and manipulation of the bowel results in a decreased production of proinflammatory cytokines that induce ileus (Delgado et al 2001). In addition, due to smaller incisions, postoperative opioid usage is decreased and the opioid-induced potentiation of POI is not as prominent. These differences routinely result in a decrease in length of stay from 1 to 2 days when randomized trials of open versus laparoscopic-assisted bowel resection are compared (Lacy et al 2002; Clinical Outcomes of Surgical Therapy Study Group 2004).

\section{Postoperative analgesia with opioids}

The mainstay of postoperative control of surgical pain is with the intravenous administration of morphine or other opioid class drugs, until they can be tolerated orally. Opioids are a double edged sword because although they provide excellent relief of postoperative pain, they exacerbate the POI through their effects on the intestine. There are three types of opioid receptors (mu, delta, kappa) and they are present in both the central nervous system and the enteric nervous system, located in the myenteric and submucosal bowel plexus (Bohn and Raehal 2006). The majority of the effect of opioid receptor to slow intestinal transit comes from its direct effects in the enteric nervous system (Manara et al 1986). Most opioid analgesics exert their analgesic effects centrally via the mu opioid receptor, and their gastrointestinal effects are also mediated via the mu opioid receptor, but located in the intestine (Bohn and Raehal 2006).

A search for a compound that can block the detrimental effect of opioid at the enteric mu receptor while permitting its analgesic function at the central mu receptor yielded the candidate drugs alvimopan (Entereg ${ }^{\circledR}$ ) and methylnaltrexone (Zimmerman et al 1994; Goodman et al 2007). Best studied of these compounds for its effects on POI is alvimopan, initially known as ADL 8-2698/LY 246736. Alvimopan is an orally administered peripherally acting mu opioid antagonist that does not cross the blood-brain barrier, thus not reversing opioid-induced analgesia. This compound has been studied for two major indications: 1) Acute administration to speed the recovery of gastrointestinal function after open abdominal surgery; 2) Chronic low dose administration to reverse the opioid-induced bowel dysfunction (OBD) and constipation from long-term opioid administration to control pain. The remainder of this article will focus on the clinical trials used to demonstrate the efficacy and safety of alvimopan to speed the recovery of gastrointestinal function after open abdominal surgery.

\section{Alvimopan postoperative ileus trials}

Several randomized trials have been used to test the hypothesis that alvimopan can reduce POI after laparotomy. While the trials differ in some respects they share many common features. The common features of the trials have created the benefit of combined analysis without significant heterogeneity in the populations.

Taguchi et al (2001) published the results of an initial study of 78 patients. This was a single institution randomized study of generally healthy patients having elective partial colectomy $(n=15)$ or total abdominal hysterectomy $(n=63)$ by open laparotomy, who were assigned to receive either placebo, $1 \mathrm{mg}$ alvimopan or $6 \mathrm{mg}$ alvimopan 2 hours prior to surgery then twice daily until the first bowel movement, discharge from the hospital, or for a maximum of 7 days. Researchers assessing the patient outcomes and the patients were blinded to group assignment but it is not clear if the treating physicians were blinded in this study. Postoperative surgical management was not dictated by any specific protocol. Median time to passage of first flatus was significantly decreased from 70 hours to 49 hours, time to 
first bowel movement decreased from 111 to 70 hours and time until patients were ready for discharge decreased from 91 to 68 hours when the placebo and $6 \mathrm{mg}$ alvimopan groups were compared. Pain scores and narcotic usage were similar between groups, while the adverse effects nausea and vomiting were significantly less common in the $6 \mathrm{mg}$ alvimopan group compared to placebo. The treatment effects were more pronounced in the $6 \mathrm{mg}$ group than the $1 \mathrm{mg}$ group versus placebo, but adverse events were not increased. Based on the results of this trial and other preliminary data, a series of multicenter randomized double blind trials was conducted with standardization of inclusion criteria, protocols, and outcome measures.

In March 2001, study 14CL302 (clinicaltrials.gov identifier NCT003888258) began to enroll patients and the results were reported by Delaney et al (2005). This trial was a randomized, double-blind, placebo-controlled, phase III trial conducted at 40 centers throughout the US. Eligible patients were scheduled to undergo partial small or large bowel resection (except low anterior resection) or hysterectomy and would receive either placebo, $6 \mathrm{mg}$ alvimopan, or $12 \mathrm{mg}$ alvimopan administered at least 2 hours before surgery and then twice daily until hospital discharge or a maximum of 7 postoperative days. Patients were excluded from participation if their procedure was a total colectomy or included an ileostomy or colostomy. Other exclusion criteria included concurrent severe medical problems, opioid use within 4 weeks of surgery, bowel obstruction or inflammatory bowel disease. Patients were excluded if a nonsteroidal anti-inflammatory drugs or epidural analgesia was planned. Postoperative care was dictated by a relatively fast-track protocol which included removal of nasogastric tubes at operation or the morning of postoperative day number one, early introduction of diet, and ambulation programs. Patient-controlled analgesia (PCA) was initially used for pain. The primary outcome measure was time to recovery of gastrointestinal function (GI-3) defined as the later of the following two events: time that the patient first tolerated solid food (recovery of upper gastrointestinal function) and time that the patient first passed flatus or a bowel movement. Additional outcome measures included time to hospital discharge order and so called GI-2 defined as the later of the following two events: toleration of solid food and passage of a bowel movement. Modified intention to treat analysis was applied to test for efficacy. 451 patients were randomized into the 3 arms of the study with $15.8 \%-26.7 \%$ patients per group discontinuing treatment. Discontinuation of treatment due to adverse events was similar between the placebo and $12 \mathrm{mg}$ group but lower in the $6 \mathrm{mg}$ group, and protocol violations accounted for the majority of other treatment discontinuations. $67.5 \%$ of patients had bowel resection and $28.7 \%$ of patients had simple or radical hysterectomy. Mean time to gastrointestinal recovery (GI-3) was significantly lower (86.2 hours) in the $6 \mathrm{mg}$ alvimopan group compared with the placebo group (100.3 hours) but the decrease in the $12 \mathrm{mg}$ alvimopan group ( 92.8 hours) only represented a trend. In subgroup analysis of this study, patients undergoing hysterectomy did not have a significant decrease in their gastrointestinal recovery compared with placebo. More patients in the placebo group (20.7\%) required 6 or more days for return of bowel function compared with the $6 \mathrm{mg}(12 \%)$ or $12 \mathrm{mg}(13.1 \%)$ groups. Time to hospital discharge was decreased by 15 hours in patients treated with $6 \mathrm{mg}$ alvimopan and 14 hours for patients treated with $12 \mathrm{mg}$ compared with placebo. Patients in the placebo and $6 \mathrm{mg}$ alvimopan groups required the same amount of opioid pain medication while those in the $12 \mathrm{mg}$ group required more, but pain scores did not differ between groups. Neither of the two deaths in the treatment arms of the study were believed to be caused by the medication.

In January 2002 study 14CL313 (clinicaltrials.gov identifier NCT00388401) began to enroll patients and the results were reported by Wolff et al (2004). This also was a randomized, double-blind, placebo-controlled, parallel group study of 34 centers in the North America. Inclusion criteria, exclusion criteria, postoperative management and outcome measures were nearly identical to trial 14CL302 except inflammatory bowel disease surgery and rectal surgery were permitted, and simple hysterectomy was excluded. The intention to treat population in this study was 469 patients and the most common operation was colon resection (84\%) followed by small bowel resection (12\%) and radical hysterectomy (4\%). In this study, return of gastrointestinal function (GI-3) was significantly shortened by 15 hours in the $6 \mathrm{mg}$ alvimopan group and 22 hours in the $12 \mathrm{mg}$ alvimopan group compared with placebo. GI-2 was significantly faster in both treatment groups and hospital discharge was earlier by 13 hours in the $6 \mathrm{mg}$ group and 20 hours in the $12 \mathrm{mg}$ group compared with placebo patients. Patients in the $12 \mathrm{mg}$ alvimopan group used the same amount of narcotics as the placebo group, but there were more narcotics used by the $6 \mathrm{mg}$ group. Pain scores were not different among groups. Statistically fewer patients required nasogastric tube placement in the $12 \mathrm{mg}$ alvimopan group (4.8\%) compared with placebo (14.8\%). Adverse events were similar between groups. 
In December 2001, study 14CL308 (clinicaltrials.gov identifier NCT00388479) was started and the results were reported by Viscusi et al (2006). This trial was similar in design and administration to the previous two trials (14CL302 and 14CL313) and over 600 patients were randomized between the three arms (placebo, $6 \mathrm{mg}$ alvimopan and $12 \mathrm{mg}$ alvimopan). In the initial analysis alvimopan did not significantly accelerate recovery of gastrointestinal function. However, when an analysis that controlled for the covariates sex and operative duration, alvimopan $6 \mathrm{mg}$ was found to speed gastrointestinal recovery by 7.5 hours and alvimopan $12 \mathrm{mg}$ speeded recovery by 9.9 hours compared to placebo. Male sex and longer operative duration were associated with longer times for return of bowel function. Faster GI-2 and shorter times to discharge were also seen with both alvimopan groups when controlled for these confounding variables. Pain scores, opioid usage, and adverse events did not differ.

A pooled analysis analysis of these three trials (14CL302, 14CL308 and 14CL313) was performed by Delaney et al (2007). One advantage of the similarities in trial design is that concerns about heterogeneity of patients in pooling the results are minimal. For this analysis, the 1212 patients in the three trials undergoing bowel resection were compared. The pooled results were significant and universally favorable in that both the $6 \mathrm{mg}$ and $12 \mathrm{mg}$ dosing of alvimopan resulted in a faster return of gastrointestinal recovery (GI-3; 12.4 and 14.8 hours, respectively), faster time to bowel movement (GI-2; 15 and 18.3 hours, respectively), and discharge orders written (16 and 18.4 hours, respectively). Postoperative ileus, nasogastric tube insertion and hospital readmission were all lower for both alvimopan groups versus placebo. There were no differences in adverse events, opioid usage or pain scores.

In June 2004 the additional study 14CL314 (clinicaltrials. gov identifier NCT00205842) was started and has since been completed (Trial identifier NCT00205842 at www. clinicaltrials.gov). The results have been used in published analysis of aggregate trial results, but to date have only been independently published in poster form and not as an a full length manuscript (Ludwig et al 2006). The study has some differences from the three that preceded it. Only patients having a small or large bowel resection by open laparotomy were eligible, no longer including any patients having a hysterectomy. While the study consisted of a placebo, $6 \mathrm{mg}$ and $12 \mathrm{mg}$ arm, the drug is dosed from 30-90 minutes prior to surgery as opposed to at least 2 hours in previous studies. Additional exclusion criteria include patients with a history of gastrectomy, short bowel syndrome or multiple previous open abdominal surgeries. Outcome measures and definitions were not changed, and results were similar to those noted in previous trials and in the previously described pooled analyses.

To address the issue of the safety and efficacy of alvimopan in speeding the return of gastrointestinal function after hysterectomy, a separate trial was devised and the results reported by Herzog et al (2006). In this trial, 519 women were randomized 4:1 to receive either alvimopan $12 \mathrm{mg}$ or placebo 2 hours before hysterectomy by laparotomy and had treatment continued for 7 days postoperatively. One major difference was that patients would continue taking the drug/placebo at home for a total of 7 days if discharged, which most of them were. The rationale for this was that the average length of stay for hysterectomy was short and many patients appeared as censored observations - they did not meet the endpoint (return of bowel function) prior to discharge from the hospital and completion of the study. Patients kept journals at home regarding their symptoms and bowel functions. Adverse events, opioid usage, and pain scores were no different between groups. Recovery of gastrointestinal function (GI-3), toleration of solid food, or hospital discharge times were not different between groups. Mean time to first bowel movement was faster in the alvimopan group by 20.2 hours. Laxative use was higher in the placebo group and a larger percentage of the alvimopan-treated patients were ambulatory for more than an hour a day.

GSK001 was a study similar to the four previous North American studies but was instead a multicenter European trial. The results were published by Büchler et al (2008). It was a randomized, double-blind, placebo controlled, parallel group study involving over 900 patients at 70 hospitals in 11 countries in Europe and elsewhere. Initially the inclusion criteria were similar to the previous North American studies in that patients undergoing small or large bowel resection or hysterectomy by laparotomy were eligible. This was modified to include only patients having bowel resection on the basis of data analyzed from the North American studies. Patients were randomized to receive either placebo, $6 \mathrm{mg}$ alvimopan or $12 \mathrm{mg}$ alvimopan 2 hours before surgery and twice daily after to a maximum course of 7 days. A notable difference in postoperative care protocols from previous trials permitted the use of nonsteroidal anti-inflammatory medications which ended up being used in $69 \%$ of patients. In addition, use of PCA was not required and was only present in $45 \%$ of patients. The remainder of patients had some form of nurse-administered opioid pain control. The primary outcome measure was mean time to return of gastrointestinal function (GI-3) which was reduced by 8.5 hours in the $6 \mathrm{mg}$ 
alvimopan group and 4.8 hours in the $12 \mathrm{mg}$ alvimopan group compared to placebo. When using the Hochberg correction for multiple comparisons, both results were not found to be statistically significant. Mean time to toleration of solid food and first bowel movement (GI-3) was significantly decreased by 14.3 hours in the $6 \mathrm{mg}$ alvimopan groups and 10.7 hours in the $12 \mathrm{mg}$ alvimopan group compared with placebo. Patients in the PCA group received more opioid than the non-PCA groups, although pain scores did not differ. In the PCA subgroup of patients, time to return of gastrointestinal function (GI-3) was decreased in both the $6 \mathrm{mg}$ alvimopan and $12 \mathrm{mg}$ alvimopan group. Adverse events were not different between groups.

Senagore et al (2007) published the pooled data analysis from the four North American trials (14CL302, 14CL308, 14CL313, 14CL314) and the one European trial (GSK001). The subgroup analyzed were patients undergoing bowel resection and either receiving placebo or $12 \mathrm{mg}$ alvimopan by the previously described dosing schedule. The baseline characteristics are summarized in Table 1. One interesting observation was that patients aged over 65 years, male patients, and nonwhite patients had a significantly longer time to return of gastrointestinal function (GI-3) while the time to first bowel movement (GI-2) showed a similar trend but was not significant. Alvimopan speeded GI-3, GI-2, and time to hospital discharge in the pooled analysis and in subgroups of patients regardless of gender, age, or ethnicity, as demonstrated in Figure 1. These beneficial effects of alvimopan versus placebo were preserved in groups receiving perioperative antibiotics, mechanical bowel preparation, histamine receptor antagonists, and proton pump inhibitors. These were specifically noted because these interventions have been associated with lower effective level of drug doses in practice (Foss et al 2008). No adverse events were more common among the pooled alvimopan groups compared to placebo but the adverse events nausea, vomiting, or POI were more common in patients receiving placebo, as shown in Table 2.

An independent group of surgical researchers with experience in meta-analysis techniques analyzed the series of alvimopan trials (Tan et al 2006). The five studies meeting their criteria included the first three North American trials (14CL302, 14CL308 and 14CL313) in additional to the trial on hysterectomy patients reported by Herzog et al (2006) and the single center study published by Taguchi et al (2001) and included over 2000 patients. The authors believed this to be a good subject for pooled analysis because of minimal heterogeneity in the studies and their finding of only small variation in the hazard ratios for return of bowel function to indicate that the studies are suitable for pooling data. Their conclusion was that gastrointestinal recovery (GI-3), time to first bowel movement (GI-2), and

Table I Patient demographics and baseline characteristics for patients undergoing bowel resection in phase III trials (modified-intent-to-treat population). Reproduced with permission from Senagore A, Bauer J, Du W, et al 2007. Alvimopan accelerates gastrointestinal recovery after bowel resection regardless of age, gender, race or concomitant medication use. Surgery, 142:478-86. Copyright (C) 2007 Mosby, Inc

\begin{tabular}{|c|c|c|c|c|c|c|}
\hline & $\begin{array}{l}\text { I4CL302 } \\
(N=197)\end{array}$ & $\begin{array}{l}\text { I4CL308 } \\
(N=28 I)\end{array}$ & $\begin{array}{l}\text { I4CL3 I } 3 \\
(N=302)\end{array}$ & $\begin{array}{l}\text { GSKO0I } \\
(N=468)\end{array}$ & $\begin{array}{l}|4 C L 3| 4 \\
(N=629)\end{array}$ & $\begin{array}{l}\text { Overall } \\
(N=1877)\end{array}$ \\
\hline \multicolumn{7}{|l|}{ Age (y) } \\
\hline Mean \pm SD & $61.7 \pm 12.8$ & $60.5 \pm 15.5$ & $61.4 \pm 14.6$ & $63.9 \pm 12.6$ & $59.8 \pm \mid 4.1$ & $61.4 \pm 14.0$ \\
\hline$\geq 65, n(\%)$ & $83(42.1)$ & $125(44.5)$ & I 44 (47.7) & $246(52.6)$ & $247(39.3)$ & $845(45.0)$ \\
\hline$\geq 75, n(\%)$ & $37(18.8)$ & $53(18.9)$ & $58(19.2)$ & $96(20.5)$ & $91(14.5)$ & $335(17.8)$ \\
\hline \multicolumn{7}{|l|}{ Race, $n$ (\%) } \\
\hline White & $169(85.8)$ & $223(79.4)$ & $267(88.4)$ & $462(98.7)$ & $529(84.1)$ & I,650 (87.9) \\
\hline Nonwhite & $28(14.2)$ & $58(20.6)$ & $35(11.6)$ & $(1.3)$ & $100(15.9)$ & $227(12.1)$ \\
\hline \multicolumn{7}{|l|}{ Gender, $n$ (\%) } \\
\hline Female & $108(54.8)$ & I 37 (48.8) & $155(5 \mid .3)$ & $210(44.9)$ & $320(50.9)$ & $930(49.5)$ \\
\hline \multicolumn{7}{|l|}{ BMI } \\
\hline Mean $\pm S D, k g / \mathrm{m}^{2}$ & $28.2 \pm 5.8$ & $27.5 \pm 6.2$ & $27.8 \pm 5.9$ & $26.5 \pm 4.5$ & $28.4 \pm 6.3$ & $27.7 \pm 5.8$ \\
\hline$\geq 30$ kg/m², n (\%) & $68(34.5)$ & $73(26.0)$ & $83(27.5)$ & $83(17.7)$ & $210(33.4)$ & $517(27.5)$ \\
\hline \multicolumn{7}{|l|}{ Surgery type, $n(\%)$} \\
\hline Small BR & - & $27(9.6)$ & $35(11.6)$ & $21(4.5)$ & $53(8.4)$ & $136(7.2)$ \\
\hline Large BR & $197(100.0)$ & $254(90.4)$ & $267(88.4)$ & $447(95.5)$ & $576(91.6)$ & $\mathrm{I}, 74 \mathrm{I}(92.8)$ \\
\hline Surgery duration (h) & $2.0 \pm 1.0$ & $2.5 \pm 1.2$ & $2.1 \pm 1.1$ & $2.6 \pm 1.1$ & $2.0 \pm 1.1$ & $2.2 \pm I .1$ \\
\hline Overall mean $\pm S D$ & & & & & & \\
\hline
\end{tabular}

Abbreviations: BMI, body mass index; BR, bowel resection; SD, standard deviation.

Therapeutics and Clinical Risk Management 2008:4(5) 
A
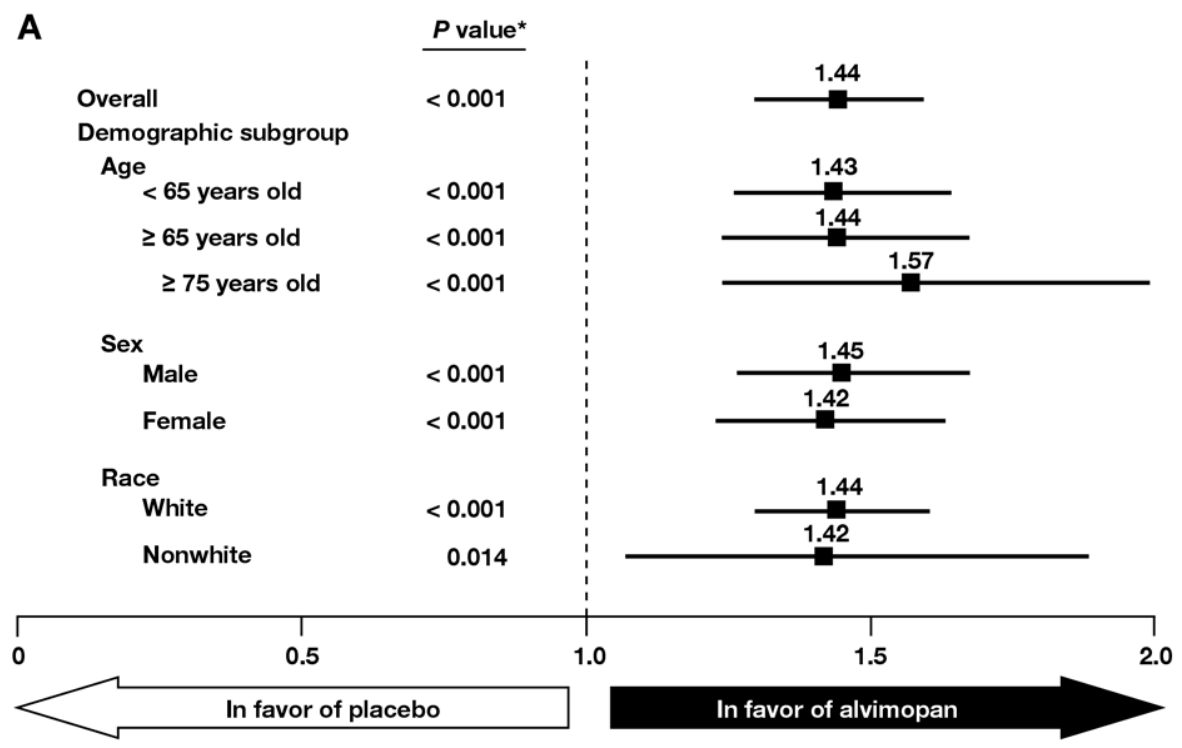

B

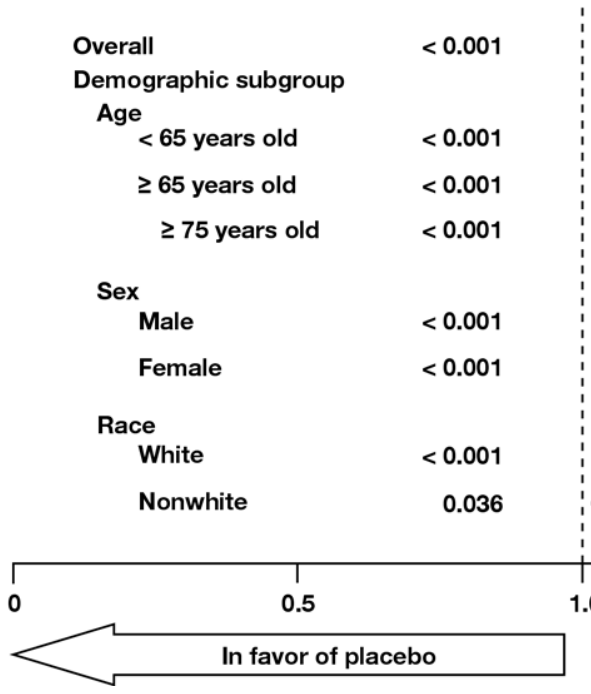

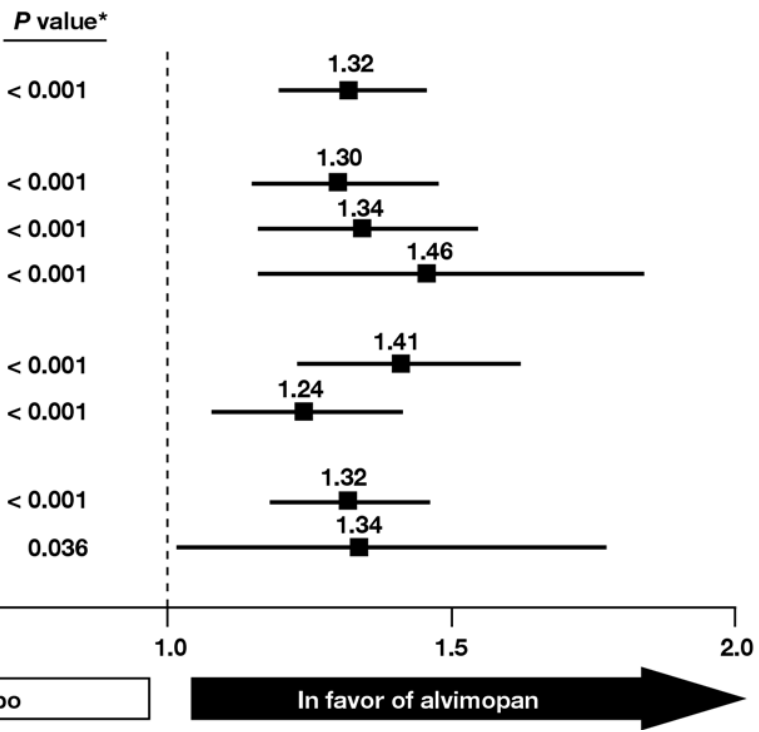

Figure I Alvimopan 12-mg treatment effect on time to gastrointestinal recovery within demographic subgroups: Hazard ratios for time to GI-2 (A) and GI-3 (B) recovery. $\mathrm{Gl}-2$, time to first toleration of solid food and time to first bowel movement; $\mathrm{Gl}-3$, time to first toleration of solid food and time to first bowel movement or flatus. ${ }^{2} \mathrm{P}$ values compare alvimopan $12 \mathrm{mg}$ versus placebo within subgroups. Reproduced with permission from Senagore A, Bauer J, Du W, et al 2007. Alvimopan accelerates gastrointestinal recovery after bowel resection regardless of age, gender, race or concomitant medication use. Surgery, I42:478-86. Copyright @ 2007 Mosby, Inc.

time to discharge order were faster, whereas postoperative narcotic usage, pain scores, and adverse events were no different when $12 \mathrm{mg}$ alvimopan was compared with placebo.

The Cochrane Collaboration has recently analyzed the topic of the efficacy and safety of pharmacologic treatment of adynamic ileus after abdominal surgery (Traut et al 2008). 14 different pharmacologic treatments were evaluated, including alvimopan. The overall quality of the studies was judged to be moderate, deficiencies in methodology or reporting of the randomization and blinding process being cited as deficiencies. In discussion with some of the study investigators, this observation is a reporting deficiency, as randomization and blinding in the trials were performed according to accepted convention. Lastly, the facts that the studies had received funding from the pharmaceutical company responsible for developing the compound and that some coauthors were employees of the company were noted. Despite this, they did acknowledge that alvimopan may be likely to reduce the time to recovery of bowel function after major abdominal surgery.

\section{Safety}

In the POI trials, alvimopan was judged to be very safe with no difference in adverse event rates from placebo (Senagore 
Table 2 Treatment-emergent adverse events reported in $\geq 5 \%$ of patients undergoing bowel resection. Reproduced with permission from Senagore A, Bauer J, Du W, et al 2007. Alvimopan accelerates gastrointestinal recovery after bowel resection regardless of age, gender, race or concomitant medication use. Surgery, I42:478-86. Copyright @ 2007 Mosby, Inc

\begin{tabular}{|c|c|c|c|c|}
\hline \multirow[b]{3}{*}{ Adverse event } & \multicolumn{4}{|c|}{ Patients, $n$ (\%) } \\
\hline & \multicolumn{2}{|c|}{ North American trials* } & \multicolumn{2}{|c|}{ European trial ${ }^{\dagger}$} \\
\hline & $\begin{array}{l}\text { Placebo } \\
(n=695)\end{array}$ & $\begin{array}{l}\text { Alvimopan } 12 \mathrm{mg} \\
(n=7 \mid 4)\end{array}$ & $\begin{array}{l}\text { Placebo } \\
(n=292)\end{array}$ & $\begin{array}{l}\text { Alvimopan } 12 \mathrm{mg} \\
(n=297)\end{array}$ \\
\hline Nausea & $454(65.3)$ & $399(55.9)^{\ddagger}$ & $21(7)$ & $28(9)$ \\
\hline Vomiting & $188(27.1)$ & $134(18.8)^{\ddagger}$ & $21(7)$ & $13(4)$ \\
\hline Abdominal distension & $127(\mid 8.3)$ & $110(15.4)$ & NR & NR \\
\hline Pyrexia & $122(17.6)$ & $88(12.3)$ & $17(6)$ & $16(5)$ \\
\hline POI & $107(15.4)$ & $57(8.0)^{\ddagger}$ & NR & NR \\
\hline Hypertension & $101(14.5)$ & $100(14.0)$ & $14(5)$ & $19(6)$ \\
\hline Postoperative wound infection & $66(9.5)$ & $48(6.7)$ & II (4) & $14(5)$ \\
\hline
\end{tabular}

POI, postoperative ileus; NR, not reported.

*Based on pooled modified intent-to-treat population.

${ }^{\dagger}$ Based on safety population.

$\ddagger P<0.00$ I; $P$-values calculated using Fisher's exact test.

et al 2007). As expected, the most common adverse events in the trials were nausea and vomiting, but these were less common in the alvimopan-treated groups. The pooled data do not raise any safety concerns regarding cardiovascular events, neoplasms, or fractures.

The primary concern about the safety of alvimopan was derived from the adverse event profiles of randomized trials of alvimopan to reduce the symptoms of OBD. In one study, patients were treated with a low dose of alvimopan $(0.5 \mathrm{mg}$ twice a day) for a 12-month period. In this study, there were more cardiac-related adverse events such as myocardial infarction in the 538-patient treatment arm compared to the 267 placebo patients, but it was not significant (http://www. fda.gov/ohrms/dockets/ac/08/slides/2008-4336s1-04-AdolorMortensen.pdf). When these data were pooled with several similar studies of alvimopan in OBD, the trend is less striking. In this same study, neoplasms tended to be more common in the alvimopan-treated group but this also did not reach statistical significance. In studies specifically with cancer pain, a trend towards increased number of deaths in the alvimopan group was noted, but the studies were not controlled for factors known to favor disease progression. In multivariate analysis, alvimopan was not found to be a significant predictor for risk of death. Lastly fractures seemed to be more common in the alvimopan-treated group in these studies but total numbers of events were small.

\section{Regulatory approval}

In May 2008, the Food and Drug Administration (FDA) concluded a series of hearings on the efficacy and safety of alvimopan in the treatment of POI, and approved its use (Press release May 20, 2008). The drug was approved with a Risk Evaluation and Mitigation Strategy (REMS) for continued monitoring and to ensure that the benefits of the drug outweigh the risks. The approved indication was for a $12 \mathrm{mg}$ dose to be administered preoperatively to patients scheduled to undergo small or large bowel obstruction by open laparotomy. The treatment can continue twice daily for a total of 7 days, but can be administered only in the hospital and is not approved for use on outpatients. In addition, hospitals must be specially certified to dispense the drug and educational materials must be given to health care workers. Efficacy data was examined from the POI trials and safety data was used from all trials including long-term low dose trials to treat opioid induced constipation.

\section{Comment}

Randomized surgical trials are difficult to control and expensive to complete. Despite their obvious financial interest in success of alvimopan, Aldolor and GlaxoSmithKline should be commended for their commitment to an academic approach to the study of the safety and efficacy of this drug. Even pooled analysis of the placebo groups from their trials have been used to gain a better understanding of what is normal recovery from open gastrointestinal surgery (Wolff et al 2007). The homogeneity of the trials and data make a strong case that alvimopan $12 \mathrm{mg}$ twice a day will decrease the time to return of gastrointestinal function and thus hospital discharge by roughly 12 hours in patients having open segmental bowel resection. Unfortunately, these trials are

Therapeutics and Clinical Risk Management 2008:4(5) 
chasing after the moving target of advances in perioperative surgical care. Nonsteroidal anti-inflammatory agents are now used in most 'fast-track' recovery protocols as they have a narcotic sparing effect. When these drugs were permitted in the European trial of alvimopan, the treatment effect was less robust, particularly in patients who were not using a PCA and had lower opiate doses after surgery. Furthermore, an increasing percentage of bowel resections in patients without prior surgery are now performed laparoscopically with decreased use of narcotic pain medicine and reduced length of stay (Delaney et al 2008). To date, there are no clinical trial data for the use of alvimopan in laparoscopic surgery patients, and with the lower opiate doses required, it is currently unclear whether a benefit will be noted.

Issues with safety noted in the chronic OBD population are undergoing further analysis. Almost all events were noted in a single trial, and likely related to vagaries of this trial alone. No such events have been substantiated in the more than 2000 patients receiving short acute course for POI.

Despite these shortcomings, an 18-hour acceleration of gastrointestinal recovery, with consequent decrease in length of stay may have the ability to reduce hospital stay by three days for every two intestinal resectional surgery patients. This has the potential to save significant health care dollars, depending on the cost of administration of the drug, and also increase bed availability by getting patients home earlier. In addition, the hysterectomy trial outpatient data indicated that patients who received alvimopan had a more durable and symptom-free bowel function during the early days of their recovery at home and this benefit has value. Continued usage and monitoring will alleviate safety concerns.

What may be even more important is that alvimopan may allow more predictable recovery of gastrointestinal function, and more predictable discharge. One of the findings noted in many studies was that the number of patients with prolonged recovery (hospital stay greater than 7 days) was significantly reduced with alvimopan. The number of readmissions was also reduced by $50 \%$ in some trials (Wolff et al 2004). As prolonged stay and readmission are two of the major adverse events related to major bowel surgery, and certainly two of the primary outcomes that reduce our ability to standardize care, alvimopan may permit surgeons and hospitals to improve the overall quality and efficiency of care they provide.

Finally, alvimopan is currently alone, in that there are no other medications that have been shown with this degree of scientific rigor to be effective in speeding the return in gastrointestinal function after abdominal surgery.
Having recently been FDA approved, it appears to have robust efficacy and safety data, showing clinical benefit in patients undergoing segmental small or large bowel resection by laparotomy who are planned to have PCA. Cost of the medication will now determine how it can be integrated into hospital care pathways. Future studies will need to address cost-effectiveness in practice and perhaps more important, the benefit of alvimopan in those having laparoscopic intestinal surgery.

\section{Disclosures}

Dr. Delaney has been Principal Investigator on alvimopan clinical trials and received research funding for these. $\mathrm{He}$ is also a consultant to Adolor Corporation, Exton, Pennsylvania and GlaxoSmithKline, Philadelphia, Pennsylvania. Dr. Marderstein has no disclosures.

\section{References}

Basse L, Thorbøl JE, Løss1 K, et al. 2004. Colonic surgery with accelerated rehabilitation or conventional care. Dis Colon Rectum, 47:271-7.

Bohn L, Raehal K. 2006. Opioid receptor signaling: relevance for gastrointestinal therapy. Curr Opin Pharmacol, 6:559-63.

Büchler M, Seiler C, Monson J, et al. 2008. Clinical trial: alvimopan for the management of postoperative ileus after abdominal surgery: results of an international randomized, double-blind, multicentre, placebo-controlled clinical trial. Aliment Pharmacol Ther [Epub March 25].

Clinical Outcomes of Surgical Therapy Study Group. 2004. A comparison of laparoscopically assisted and open colectomy for colon cancer. N Engl J Med, 350:2050-9.

Delaney CP, Chang E, Senagore AJ, et al. 2008. Clinical outcomes and resource utilization associated with laparoscopic and open colectomy using a large national database. Ann Surg, 247:819-24.

Delaney CP, Fazio VW, Senagore AJ et al. 2001. 'Fast track' postoperative management protocol for patients with high co-morbidity undergoing complex abdominal and pelvic colorectal surgery. Br J Surgery, 88:1533-8.

Delaney CP, Kehlet H, Senagore A, et al. 2006. Postoperative ileus: profiles, risk factors and definitions - a framework for optimizing surgical outcomes in patients undergoing major abdominal and colorectal surgery. Clinical Consensus Update in General Surgery. May 1, 2006

Delaney CP, Kiran RP, Senagore AJ, et al. 2003. Case-matched comparison of clinical and financial outcome after laparoscopic or open colorectal surgery. Ann Surg, 238:67-72.

Delaney CP, Weese JL, Hyman NH, et al. 2005. Phase III trial of alvimopan, a novel peripherally acting, mu opioid antagonist, for postoperative ileus after major abdominal surgery. Dis Colon Rectum, 48:1114-29.

Delaney CP, Wolff B, Viscusi E, et al. 2007. Alvimopan, for postoperative ileus following bowel resection: a pooled analysis of phase iii studies. Ann Surg, 245:355-63.

Delaney CP, Zutshi M, Senagore AJ et al. 2003. Prospective, randomized, controlled trial between a pathway of controlled rehabilitation with early ambulation and diet and traditional postoperative care after laparotomy and intestinal resection. Dis Colon Rectum, 46:851-9.

Delgado S, Lacy AM, Filella X et al. 2001. Acute phase response in laparoscopic and open colectomy in colon cancer: a randomized study. Dis Colon Rectum, 44:638-46.

FDA approves Entereg to help resore bowel function following surgery. Press release May 20, 2008. www.fda.gov/bbs/topics/NEWS/2008/ NEW01838.html. 
Foss J, Fisher D, Schmith V. 2008. Pharmacokinetics of alvimopan and its metabolite in healthy volunteers and patients in postoperative ileus trials. Clin Pharm Ther, 83:770-6.

Goodman AJ, Le Bourdonnec B, Dolle RE. 2007. Mu opioid receptor antagonists: recent developments. Chem Med Chem, 11:1552-70.

Herzog T, Coleman R, Guerrieri J, et al. 2006. A Double-blind, randomized, placebo-controlled phase iii study of the safety of alvimopan in patients who undergo simple total abdoinal hysterectomy. Am JObstet Gynecol, 195:445-53.

Kalff JC, Schraut WH, Simmons RL, et al. 1998. Surgical manipulation of the gut elicits an intestinal muscularis inflammatory response resulting in postsurgical ileus. Ann Surg, 228:652-63.

Lacy AM, García-Valdecasas J, Delgado S, et al. 2002. Laparoscopy-assisted colectomy versus open colectomy for treatment of non-metastatic colon cancer: a randomized trial. Lancet, 359:2224-9.

Ludwig K, Enker WE, Delaney CP, et al. Accelerated gastrointestinal recovery and reduced length of stay following modified preoperative dose timing with Alvimopan: results of a large, randomized, placebocontrolled study in partial bowel resection [Poster]. Annual Clinical Congress of the American College of Surgeons, October 2006. Chicago, IL. Poster SE120.

Manara L, Bianchi G, Ferretti P. 1986. Inhibition of gastrointestinal transit by morphine in rats results primarily from direct drug action on gut opioid sites. J Pharmacol Exp Ther, 237:945-9.

Senagore A, Bauer J, Du W, et al. 2007. Alvimopan accelerates gastrointestinal recovery after bowel resection regardless of age, gender, race or concomitant medication use. Surgery, 142:478-86.

Taguchi A, Sharma N, Saleem RM, et al. 2001. Selective postoperative inhibition of gastrointestinal opiod receptors. N Engl J Med, 345:935-40.

Tan E, Cornish J, Darzi A, et al. 2006. Meta-analysis: alvimopan vs placebo in the treatment of post-operative ileus. Aliment Pharmacol Ther, 25:47-57.
Traut U, Brügger L, Kunz R, et al. 2008. Systemic prokinetic pharmacologic treatment for postoperative adynamic ileus following abdominal surgery in adults. The Cochrane Collaboration: 1.http://www.fda.gov/ohrms/ dockets/ac/08/slides/2008-4336s1-04-Adolor-Mortensen.pdf

Trial identifier NCT00205842 at www.clinicaltrials.gov

Vermeulen H, Storm-Versloot MN, Busch OR, et al. 2006. Nasogastric intubation after abdominal surgery: a meta-analysis of recent literature. Arch Surg, 141:307-14.

Viscusi ER, Goldstein S, Witkowski T, et al. 2006. Alvimopan, a peripherally acting mu-opioid receptor antagonist, compared with placebo in postoperative ileus after major abdominal surgery. Surg Endoscopy, 20:64-70

Waldhausen JH, Schirmer BD. 1990. The effect of ambulation on recovery from postoperative ileus. Ann Surg, 212:671-7.

Wolff B, Viscusi E, Delaney C, et al. 2007. Patterns of gastrointestinal recovery after bowel resection and total abdominal hysterectomy: pooled results from the placebo arms of alvimopan phase III North American clinical trials. J Am Coll Surg, 205:43-51.

Wolff BG, Michelassi F, Gerkin TM, et al. 2004. Alvimopan, a novel, peripherally acting $\mu$ opioid antagonist: results of a multicenter, randomized, double-blind, placebo-controlled, phase iii trial of major abdominal surgery and postoperative ileus. Ann Surg, 240:728-35.

Zimmerman D, Gidda J Cantrell B, et al. 1994. Discovery of a potent peripherally selective trans-3,4, dimethyl-4-(3-hydroxyphenyl) piperidine opioid antagonist for the treatment of gastrointestinal motility disorders. J Med Chem, 37:2262-5

Zutshi M, Delaney CP, Senagore AJ, et al. 2005. Randomized controlled trial comparing the controlled rehabilitation with early ambulation and diet pathway versus the controlled rehabilitation with early ambulation and diet with preemptive epidural anesthesia/analgesia after laparotomy and intestinal resection. Am J Surg, 189:268-72. 
On-Line Early 19-08-2008 